\title{
A Neurose como Negativo da Perversão: Um Estudo das Perversões em Freud
}

\author{
Roberto Lopes Mendonça ${ }^{1}$ \\ ${ }^{1}$ Faculdade Pitágoras/Grupo UNIS, MG, Brasil. \\ Mardem Leandro Silva ${ }^{2}$ \\ ${ }^{2}$ Universidade do Estado de Minas Gerais, MG, Brasil. \\ Daniela Paula do Couto ${ }^{3}$ \\ ${ }^{3}$ Universidade Federal de Minas Gerais, MG, Brasil.
}

\author{
Carlos Eduardo Rodrigues ${ }^{4}$ \\ ${ }^{4}$ Universidade Federal de São João del-Rei, MG, Brasil. \\ Aline Aparecida Rocha Caetano ${ }^{2}$ \\ ${ }^{2}$ Universidade do Estado de Minas Gerais, MG, Brasil. \\ Elizabeth Fátima Teodoro ${ }^{4}$ \\ ${ }^{4}$ Universidade Federal de São João del-Rei, MG, Brasil.
}

Resumo: Com base na afirmação freudiana de que a neurose seria o negativo da perversão, pretende-se trazer de volta ao contexto acadêmico essa entidade nosológica que paga um preço alto devido ao nome que carrega. $\mathrm{O}$ texto se propõe a discutir a perversão no decorrer da obra freudiana, além de desmistificar detalhes da dinâmica perversa, pouco explorada atualmente. Também são abordados os textos de Lacan, em que o psicanalista francês critica a proposta freudiana com outra expressão famosa no meio psicanalítico: a do Inconsciente a céu aberto. Realizou-se uma pesquisa minuciosa em textos nos quais as expressões freudiana e lacaniana surgem, atentando-se para a terminologia original proposta por esses autores. Isto posto e tomando como base a afirmação freudiana, verificou-se a existência de perversões negativas, constituídas por fantasias de conteúdos perversos por vezes causadoras de sintomas neuróticos, em oposição às perversões positivas - ou seja, quando essas fantasias são colocadas em prática sem a presença de sentimentos de asco, vergonha ou pudor. Buscou-se, portanto, entender a dinâmica das perversões em Freud, assim como compreender os critérios delimitadores entre traços perversos e perversões propriamente ditas que ganharam um status clínico ao decorrer de sua obra, servindo de base para o desenvolvimento das demais teorias a respeito do tema em questão.

Palavras-chave: Neurose, Negativo, Perversão, Céu Aberto, Nosologia Psicanalítica.

\section{Neurosis as Negative of Perversion: A Study of Perversions in Freud}

\begin{abstract}
From the Freudian claim that neurosis would be the negative of perversion, this article seeks to bring back to the academic context this nosological entity that pays such a high price because of its name. This article seeks to discuss perversion in the course of Freud's work, besides demystifying details of the perverse dynamics, little explored at present. Moreover, the texts of Lacan will be approached, from which the French psychoanalyst criticizes the Freudian proposal with another famous expression in the psychoanalytic environment: the unconscious in the open. A detailed research was conducted in texts in which the Freudian and Lacanian expressions appear, paying attention to the original terminology proposed by these authors. Having said this, and based on the Freudian assertion, negative perversions were constituted by fantasies of perverse contents, sometimes causing neurotic symptoms, as opposed to positive perversions, that is, when these fantasies are put into practice without the presence of feelings of disgust, shame or indecency. It was sought, therefore, to understand the dynamics of the perversions in Freud and understand the delimitating criteria between perverse traits and actual perversions, which gained a clinical status in the course of his work, serving as base for the development of other theories in respect theme.
\end{abstract}

Keywords: Neurosis, Negative, Perversion, Open Sky, Psychoanalytic Nosology. 


\title{
La Neurosis como Negativa de la Perversión: Un Estudio de las Perversiones en Freud
}

\begin{abstract}
Resumen: Con base en la afirmación freudiana de que la neurosis sería lo negativo de la perversión, se pretende traer de vuelta al contexto académico esta entidad nosológica que tiene grandes consecuencias debido al nombre que lleva. El presente artículo intenta discutir la perversión en la obra freudiana, además de desmitificar detalles de la dinámica perversa, poco explorada actualmente. También se abordarán los textos de Lacan que hace críticas a la propuesta freudiana mediante otra expresión famosa en el medio psicoanalítico: la del Inconsciente a cielo abierto. Se realizó una investigación minuciosa en textos de ambos autores en que aparece la expresión, atentándose a la terminología original propuesta por ellos. Dicho esto, y con base en la afirmación freudiana, se encontraron perversiones negativas, constituidas por fantasías de contenido perverso por veces causando síntomas neuróticos, en contraposición a perversiones positivas, es decir, cuando estas fantasías se ponen en práctica sin la presencia de sentimientos de disgusto, vergüenza o pudor. Se buscó entender la dinámica de las perversiones en Freud, así como comprender los criterios delimitadores entre trazos perversos y perversiones propiamente dichas, que ganaron un status clínico en el curso de su obra, sirviendo de base para el desarrollo de otras teorías al respecto del tema en cuestión.
\end{abstract}

Palabras clave: Neurosis, Negativo, Perversión, Cielo Abierto, Nosología Psicoanalítica.

Dentre as grandes transformações causadas por Sigmund Freud em nossa visão do homem, podemos tomar sua teoria da sexualidade como grande exemplo, uma vez que causou espanto em grande parte da comunidade científica ao propor que o desenvolvimento psicológico deveria ser considerado como desenvolvimento psicossexual, o que o permitiu afirmar que a sexualidade seria inerente às vivências infantis. Ou seja, a sexualidade não seria uma vivência exclusiva do universo adulto, ao contrário: ela começaria na infância e seria prerrogativa de uma teoria sobre a gênese das psiconeuroses (Freud, 1905/1996n). Segundo Roudinesco (2016), ao usar o termo Sexualtheorie (teoria sexual), Freud marcava o rompimento com os cientistas que, até aquele momento, estudavam a sexualidade humana (a sexologia), apresentando as hipóteses científicas de então, assim como as teorias infantis, estas como fantasias para responder ao enigma da procriação. $\mathrm{O}$ mestre de Viena, de maneira bem-humorada, jogava com a ambiguidade do termo "teoria".

Após a morte de Freud, porém, muito do que era visceral em sua obra se perdeu com os trabalhos dos pós-freudianos. A tradução da obra freudiana para várias línguas também apresenta perdas, como no caso da Edição standard brasileira das obras psicológicas completas de Sigmund Freud, publicada pela editora Imago no Brasil nas últimas décadas do século XX e adaptada para o português da tradução inglesa.

Algumas décadas depois da morte de Freud, na esteira das críticas aos pós-freudianos e da leitura equivocada dos conceitos do fundador da Psicanálise, encontra-se o psicanalista Jacques Lacan e sua proposta do retorno a Freud. É interessante perceber que, segundo Lacan (1955/1998a, p. 406), "o sentido de um retorno a Freud é um retorno ao sentido de Freud”; em outras palavras, seria necessária uma leitura atenta dos conceitos freudianos e uma reavaliação do fazer psicanalítico, que levaria a psicanálise a reencontrar todo seu vigor.

Essa prática de retorno ao sentido original também implica em correções de desvios, sejam eles propriamente freudianos ou mesmo na construção de desvios lacanianos, que levaram Lacan a seus atos de leitura. Ainda que, em algum momento, elas discordassem da letra freudiana, tentavam jamais discordar do sentido freudiano. 
Este é o ponto do retorno a Freud e é com ele que retomamos a discussão da nosologia ${ }^{1}$ psicanalítica. A perversão como categoria nosológica não é diferente disso, já que passou a ser usada como um termo pejorativo, e, segundo Roudinesco e Plon (1998), os perversos foram, por muito tempo, tidos como incuráveis e não analisáveis.

Tendo em vista que a perversão enquanto categoria nosológica é geralmente entendida como sinônimo de maldade, imoralidade ou promiscuidade, é necessário que haja uma melhor compreensão do que a psicanálise realmente entende como perversão - seja em nível teórico ou clínico. Ainda mais importante seria a necessidade de contextualizar a teoria em contraste com os dias atuais, uma vez que as questões culturais, sociais, religiosas e históricas são de extrema relevância quanto à nomeação de um padrão; seja ele moral, sexual ou comportamental. De acordo com o próprio Freud (1901/1996g, p. 55),

precisamos aprender a falar sem indignação sobre o que chamamos de perversões sexuais - essas transgressões da função sexual tanto na esfera do corpo quanto na do objeto sexual. Já a indefinição dos limites do que se deve chamar de vida sexual normal nas diferentes raças e épocas deveria arrefecer tal ardor fanático.

A partir da discussão a respeito da afirmação freudiana de que a neurose seria o negativo da perversão, pretende-se trazer de volta à pesquisa acadêmica essa entidade nosológica que paga um alto preço devido ao nome que carrega. Aqui busca-se discutir, portanto, a perversão no decorrer da obra freudiana com o intuito de desmistificar detalhes da dinâmica perversa.

\section{Método}

O método psicanalítico de investigação está sempre aberto e não tem a intenção de chegar a uma verdade universal ou a conclusões específicas. Ele é um processo investigativo, não conclusivo. É um processo em que a teoria e a clínica estão sempre íntimas, indissociáveis. Vemos na pena de Freud (1923/1996c, p. 218) que "um só e mesmo procedimento servia simultaneamente aos propósitos de investigar o mal e livrar-se dele, e essa conjunção fora do comum foi posteriormente conservada pela psicanálise". Partindo desse ponto de vista desde o início de suas investigações, o método clínico define-se como ponto principal da construção teórica do fundador da psicanálise. Freud soube precisar criteriosamente o que estava em jogo na perspectiva da dinâmica conceitual:

de fato, nenhuma ciência, nem mesmo a mais exata, começa com tais definições. O verdadeiro início da atividade científica consiste antes na descrição dos fenômenos, passando então a seu agrupamento, sua classificação e sua correlação. Mesmo na fase de descrição não é possível evitar que se apliquem certas ideias abstratas ao material manipulado (Freud, 1915/1996h, p. 123).

Com tal método em mente, utilizamos, para o desenvolvimento deste artigo, textos psicanalíticos relacionados ao tema da perversão, atentando-se para a terminologia original proposta por Freud. Entre esses, referimo-nos principalmente aos textos freudianos dos Três ensaios sobre a teoria da sexualidade (Freud, 1905/1996n) e o Fetichismo (Freud, 1927/1996f), além dos outros textos que se referem, de alguma forma, à perversão; seja pela via da pulsão - como no texto metapsicológico Pulsões e destinos da pulsão (Freud, 1915/1996h) -, seja pela via da fantasia - como no texto Bate-se em uma criança ${ }^{3}$

\footnotetext{
${ }^{1}$ Utilizamos o termo "nosologia" porque nosso texto tem como foco a obra freudiana. É comum, no meio lacaniano, utilizarmos a palavra "estrutura" ou as expressões estrutura subjetiva e estruturas freudianas, como dizia o próprio Lacan. Entretanto, como Freud obviamente não é lacaniano, não há o uso específico do conceito de estrutura em seu texto. Isso dado, optarmos pelo termo nosologia como algo que poderia se referir aos dois autores de maneira geral.

${ }^{2}$ É muito comum que encontremos a Pulsão [Trieb] associada ao conceito de instinto [Instinkt] nas traduções dos textos freudianos, principalmente na Edição standard brasileira das obras psicológicas completas de Sigmund Freud, da editora Imago, utilizada como referência para o presente trabalho. Na versão brasileira, este texto traz o título Os instintos e suas vicissitudes.

${ }^{3}$ Ein Kind wird geschlagen é o título original do texto freudiano, apresentado na Edição standard brasileira [...] como Uma criança é espancada. A tradução é ruim por alguns motivos: a construção freudiana é muito precisa na questão da passividade da criança (wird, tornar-se) assim como não se trata de um espancamento, mas apenas de bater (geschlagen). Outras traduções brasileiras surgem, como Batem numa criança, da Companhia das Letras, ou o Bate-se numa criança, já comum no meio lacaniano. Entretanto, uma tradução mais literal, ainda que seja uma tradução com pouco sentido em português, seria: Uma criança torna-se batida.
} 
(Freud, 1919/1996e) -, ou mesmo diretamente, pela noção de perversão - como no texto O problema econômico do masoquismo (Freud, 1924/1996k). A intenção foi, portanto, revisitar a noção clínica de perversão em Freud além de uma correlação dela com demais conceitos fundamentais para o melhor entendimento dos textos mencionados.

Utilizamos, também, alguns textos lacanianos da época de sua primeira clínica em que o autor critica a proposta freudiana. Esses textos são fruto de aproximadamente uma década de teorização lacaniana, desde a classe do dia 14 de dezembro de 1955 , do Seminário 3 (Lacan, 1955-56/2002), até a classe de 20 de abril de 1966, do Seminário 13 (Lacan, 1965662018), passando por outros seminários nesse intervalo, além de dois textos dos Escritos (Lacan, 1998b).

\section{Resultados}

\section{Considerações freudianas acerca das perversões}

De acordo com Freud (1905/1996n), no primeiro de seus Três ensaios sobre a teoria da sexualidade, em que ele discorre sobre as aberrações sexuais, a perversão consiste num desvio do objeto e do alvo sexual normal, ou seja: um desvio da "união dos genitais no ato designado como coito, que leva à descarga da tensão sexual e à extinção temporária da pulsão sexual (uma satisfação análoga à saciação da fome)" (p. 141). Nesse sentido, tudo o que poderia fugir desse padrão cultural seria denominado como perverso. No que se refere ao desvio do objeto, estão incluídos os invertidos (homossexuais) e os indivíduos que têm como objeto pessoas sexualmente imaturas e animais (pedofilia e zoofilia). Quanto ao alvo, esses desvios podem ser definidos como atos que consistem em ir além dos limites anatômicos apropriados para o ato sexual normal (superestimação do objeto sexual, fetichismo, utilização das mucosas dos lábios e boca, utilização sexual do orifício anal e dos demais locais do corpo) e a fixação em alvos sexuais provisórios (os pares de opostos sadismo/masoquismo e voyeurismo/exibicionismo).

Entretanto, no decorrer desse mesmo texto, Freud (1905/1996n) desenvolve a ideia de que os desejos sexuais perversos fariam parte da constituição do ser humano, advindos da infância. Nesse sentido, toda criança possui uma disposição perversa polimorfa, ou, em outras palavras, obtém prazer através das denominadas pulsões parciais, que se apoiam nas principais zonas erógenas durante o desenvolvimento humano (boca, ânus e genitais), além de ambos os objetos de amor infantil (os pais), configurando uma bissexualidade comum a todos os indivíduos. Futuramente, o recalcamento desses desejos ditos perversos será o núcleo dos sintomas neuróticos, pois, nesse momento, o que advirá serão sentimentos de asco, vergonha e moralidade.

Por outro lado, já que a disposição originária é necessariamente complexa, pareceu-nos que a própria pulsão sexual seria algo composto de diversos fatores e que, nas perversões, como que se desfaria em seus componentes. Com isso, as perversões se revelaram, de um lado, como inibições do desenvolvimento normal, e de outro, como dissociações dele. Essas duas concepções foram reunidas na hipótese de que a pulsão sexual do adulto nasce mediante a conjugação de diversas moções da vida infantil numa unidade, numa aspiração com um alvo único (Freud, 1905/1996n, p. 218).

O autor salienta, portanto, que essas tendências sexuais perversas nas psiconeuroses não são resultado apenas de uma fixação em uma fase ulterior, mas também de uma regressão a estágios anteriores do desenvolvimento.

Em seu texto sobre as pulsões, Freud (1915/1996h) considera que a pulsão pode sofrer alterações em seus componentes, a saber: a) reversão ao seu oposto; b) retorno em direção ao eu; c) recalque; e d) sublimação, sendo que apenas os dois primeiros são discutidos no texto. A reversão a seu oposto diz a respeito de uma modificação quanto à meta em dois processos distintos: transformação de atividade em passividade (sadismo/masoquismo e voyeurismo/exibicionismo) e a reversão de seu conteúdo (amor/ódio). Já o retorno em direção ao Eu corresponde a um sadismo primário em forma de masoquismo. Da mesma forma, esse retorno pode ocorrer com o voyeurismo e o exibicionismo. De acordo com Freud (1915/1996h, p. 134), "a fruição da dor seria, assim, uma finalidade originalmente masoquista, que só pôde tornar-se uma finalidade pulsional em alguém que era originalmente sádico". Nesse momento de sua obra, o sadismo é, portanto, primário em relação ao masoquismo. 
Em 1919, em um artigo a respeito da origem das perversões sexuais intitulado Bate-se em uma criança, Freud ainda mantém a ideia de que o sadismo seria primário e de que o masoquismo seria um retorno desse sadismo ao Eu. As fantasias infantis de surra ${ }^{4}$ foram apresentadas como tendo origem na fase edipiana, caracterizada em seu desenvolvimento por três fases. Entretanto, o fundador da Psicanálise aprofundou-se especialmente em casos de pacientes do sexo feminino para explicar o conteúdo e o desenvolvimento de tais fantasias. Por esse viés, o primeiro tempo da fantasia é expresso pela frase "o meu pai está batendo na criança” (Freud, 1919/1996e, p. 199, grifos do autor), que logo se tornará "meu pai está batendo em uma criança que eu odeio" (p. 199, grifos do autor) - geralmente um irmão ou irmã, com o qual ela deverá dividir o amor do pai. Assim, "a ideia de o pai estar batendo nessa odiosa criança é, portanto, agradável, independentemente de ter sido realmente visto assim. Significa: 'O meu pai não ama essa criança, ama apenas a mim'” (p. 200, grifos do autor). Essa fantasia é, então, de conteúdo sádico.

Já na segunda fase, o sentimento de culpa advindo do recalcamento do amor incestuoso pelo pai - transforma o sadismo em masoquismo, representado pela frase "o meu pai está me batendo [ich werde vom Vater geschlagen]" (Freud, 1919/1996e, p. 203). Essa fantasia vem acompanhada de certo grau de prazer, apesar de não ter se tornado consciente (a fantasia). "Aqui temos, pela primeira vez, a essência do masoquismo" (p. 203). Assim como em Pulsões e destinos da pulsão (Freud, 1915/1996h), há um retorno da pulsão sádica ao Eu, tornando-se masoquista devido ao sentimento de culpa.

A terceira e última fase corresponde à fantasia de que batem em uma criança, e que essa criança indeterminada é surrada por um substituto do pai geralmente um professor ou uma figura de autoridade. Apesar de seu conteúdo aparentemente sádico, tal fantasia é de origem masoquista, pois, devido ao sentimento de culpa decorrido do recalque, o pai foi substituído por outra figura e a criança é substituída por uma criança qualquer. Assim, tal fantasia é acompanhada de atos masturbatórios, pois apresenta uma nova roupagem (Freud, 1915/1996h).
Já em Além do princípio do prazer, a partir de suas observações a respeito daquilo que denominou compulsão a repetição, Freud (1920/1996a) afirma que todo ser humano possui uma tendência a retornar a estados anteriores de desenvolvimento, almejando um apaziguamento das tensões. Essa tendência está relacionada à pulsão de morte, tal como Freud explicita em 1924 em O problema econômico do masoquismo (Freud, 1924/1996k). As pulsões estariam, portanto, divididas em pulsão de morte e pulsão de vida, sendo a segunda composta pelas pulsões sexuais e as de autoconservação.

Freud (1924/1996k) também observa que existem tensões prazerosas e descargas consideradas desprazerosas (prazer no desprazer). É nesse contexto que ele aponta haver "tensões prazerosas e relaxamentos desprazerosos de tensão. O estado de excitação sexual constitui o exemplo mais notável de um aumento prazeroso de estímulos desse tipo, mas certamente não o único" (p. 180). Logo adiante afirma que:

o prazer e o desprazer, portanto, não podem ser referidos a um aumento ou diminuição de uma quantidade (que descrevemos como 'tensão devida ao estímulo'), embora obviamente muito tenham a ver com esse fator. Parece que eles dependem, não desse fator quantitativo, mas de alguma característica dele que só podemos descrever como qualitativa. Se pudéssemos dizer o que é essa característica qualitativa, estaríamos muito mais avançados em psicologia. Talvez seja o ritmo, a sequência temporal de mudanças, elevações e quedas na quantidade de estímulo. Não sabemos (Freud, 1924/1996k, p. 180).

A partir da construção do conceito de pulsão de morte e do desenvolvimento da segunda tópica freudiana, o masoquismo passa a ser considerado primário, sendo o sadismo uma parcela de energia desviada pela libido para o mundo externo. Freud (1919/1996e) também assegura haver um masoquismo secundário, considerado como o sadismo que retorna para o Eu. Nesse sentido, o masoquismo é dividido em três categorias: a) erógeno (primário); b) feminino; e c) moral.

\footnotetext{
${ }^{4}$ A versão da Edição standard brasileira traduz o termo Schlagephantasie como fantasia de espancamento. Adotaremos a proposta das Obras incompletas de Sigmund Freud - fantasias de surra, lembrando que o verbo schlagen é melhor traduzido por "bater". A ideia de espancar, em português, ultrapassa em muito, pensando de maneira quantitativa, tanto o bater quanto o surrar. A tradução do texto nessa edição é de Maria Rita Salzano Moraes (Freud, 1919/2016).
} 
Esse último está relacionado ao sentimento de culpa, tão discutido pelo autor no texto de 1919. Desse modo:

podemos traduzir a expressão 'sentimento inconsciente de culpa' como significado de uma necessidade de punição às mãos de um poder paterno. Sabemos agora que o desejo, tão frequente em fantasias, de ser surrado [geschlagen] pelo pai se situa muito próximo do outro desejo, o de ter uma relação sexual passiva (feminina) com ele, e constitui uma deformação regressiva deste último (Freud, 1924/1996k, p. 189, grifo do autor).

Apesar disso, o masoquismo moral não apresenta conteúdos sexuais manifestos, estando mais relacionado a uma necessidade de punição - seja ela através de um sintoma ou um casamento infeliz. Como trata-se de um artigo incluso já na segunda tópica de sua obra, Freud (1924/1996k) teoriza a respeito de um Supereu herdeiro do complexo de Édipo, também relacionado ao sentimento de culpa. O Eu, por sua vez, possui características masoquistas e está sempre em busca de punição - seja de um Supereu sádico, seja de situações do mundo externo. Essa busca por punição é, entretanto, inconsciente, pois remete a um desejo de ser punido pelo pai e, mais profundamente, de manter uma relação incestuosa com ele.

O masoquismo feminino, por sua vez, apresenta-se como uma fantasia "de ser amordaçado, amarrado, dolorosamente surrado [geschlagen], açoitado, de alguma maneira maltratado, forçado à obediência incondicional, sujado e aviltado" (Freud, 1924/1996k, p. 181), tal como uma criança travessa. O masoquismo feminino está, portanto, segundo o autor, baseado no masoquismo erógeno ou primário, ou seja, vinculado à pulsão de morte. Como mencionado anteriormente, a libido direciona essa pulsão autodestrutiva para o mundo externo, configurando-se o sadismo.

Alguns anos depois, em seu texto sobre o Fetichismo, Freud (1927/1996f) desenvolve a ideia de que o fetiche corresponde a uma substituição simbólica do falo da mãe, que teria sido castrada por um objeto relacionado a esse falo. $\mathrm{O}$ indivíduo, que teme a castração, recusa o fato de sua mãe não possuir um falo, pois isso significa que seu próprio pênis corre perigo. $O$ mecanismo da perversão, então, passa a ser reconhecido por Freud como o desmentido [Verleugnung ${ }^{5}$, no qual a crença de que a mãe foi castrada ainda continua preservada, mas foi, concomitantemente, abandonada. Ou seja, algo foi desmentido, mas sem que a verdade seja revelada. Dessa forma, para a criança, "a mulher teve um pênis, a despeito de tudo, mas esse pênis não é mais o mesmo de antes. Outra coisa tomou seu lugar, foi indicada como seu substituto, por assim dizer, e herda agora o interesse anteriormente dirigido a seu predecessor" (Freud, 1927/1996f, p. 157, grifos do autor).

Nesse momento da teorização freudiana, a perversão já possui um status diferenciado, próximo do que chamamos, a partir das leituras lacanianas, de estrutura subjetiva. Nesse ponto, a perversão já é uma entidade clínica isolada, bem definida e possui um mecanismo de defesa específico, diferentemente da neurose. Nesta, a defesa é efetuada pelo recalque; naquela, pelo desmentido. Ainda há alguns pontos obscuros, dado que o mecanismo de defesa da perversão é o mesmo da psicose - mas, claramente, neurose e perversão seguem caminhos opostos na nosologia freudiana.

\section{A neurose como negativo da perversão}

Uma expressão presente na obra de Freud diz respeito ao fato de que a neurose se constitui como o negativo da perversão. Isso é trabalhado pelo fundador da Psicanálise principalmente no primeiro dos Três ensaios de 1905, no qual são apresentadas as ideias de perversões negativas e perversões positivas. A presença de tendências perversas em indivíduos neuróticos é, portanto, denominada perversão negativa, em oposição às perversões propriamente ditas ou positivas. Parece-nos, assim, que Freud (1905/1996n) sugere que há uma tendência do neurótico em negar seus impulsos perversos ao elaborar o axioma de que “a neurose é [...] o negativo da perversão" (p. 157).

Essa ideia também é apresentada por Freud (1996g/1905[1901]) no Fragmento da análise de um caso de histeria, em Moral sexual 'civilizada' e doença nervosa moderna (Freud, 1908/1996i), no caso clínico sobre a Análise de uma fobia em um menino de cinco anos (Freud, 1909/1996b), na quarta das Cinco

\footnotetext{
${ }^{5}$ A palavra Verleugnung é uma das mais aleatoriamente traduzidas na obra freudiana. Traduz-se por rejeição, como no texto sobre o Fetichismo (Freud, 1996f/1927), por recusa da realidade, denegação, negação. Temos uma proposta interessante de tradução que adota o português desmentido, uma das possíveis traduções do verbo verleugnen-desmentir. O verbo leugnen, raiz de verleugnen, também tem o sentido de contestar, negar.
} 
lições de psicanálise (Freud, 1909/1996d) e, por fim, em Sobre a psicanálise (Freud, 1911/19961).

Nesse ponto, cabe uma nota sobre as palavras de Freud (1905/1999, p. 65): “die Neurose ist [...] das Negativ der Perversion". Negativ, em maiúsculo, é um substantivo. É nesse sentido que usamos, ou pelo menos usávamos, quando falamos das fotografias: a fotografia revelada é o contrário do negativo, que se obtém com o filme fotográfico. Nesse processo, há a inversão das cores: as áreas escuras de um ficam claras no outro, e vice-versa. É um processo que transforma uma imagem em seu avesso. Com isso, podemos entender melhor a afirmação freudiana de que as tendências perversas do neurótico são negativas, enquanto a perversão propriamente dita é positiva.

É necessário, contudo, abrirmos um parêntese para que seja realizada uma diferenciação terminológica entre negativo [Negativ] e negação [Verneinung]. O segundo conceito é discutido por Freud (1925/1996j) no texto $A$ negaçã $0^{6}$, em que aborda uma tendência do aparelho psíquico a negar conteúdos recalcados que, por vezes, apresentam-se na consciência sob o caráter de negação. Quando, por exemplo, um paciente de Freud é questionado sobre a identidade de determinada pessoa em um sonho, o mesmo já afirmava: “nãoé minha mãe" (Freud, 1925/1996j, p. 267, grifos do autor), como forma de repúdio a essa ideia, mas também como forma de afirmação da mesma. "É como se o paciente tivesse dito: 'é verdade que minha mãe veio à lembrança quando pensei nessa pessoa, porém não estou inclinado a permitir que essa associação entre em consideração" (p. 267). Por fim, é importante salientar que, tanto a negação quanto o negativo também diferem do desmentido [Verleugnung], que se encontra erroneamente traduzido por negação, denegação ou recusa, aumentando ainda mais a confusão terminológica.

Pensamos, portanto, ao retomar nossa discussão, que as fantasias presentes na perversão são tidas de forma consciente e transformadas em ações diante das situações favoráveis. Isso nos direciona ao entendimento de uma perversão positiva, que vai para além das tendências recalcadas do neurótico.

Essa proposta já estava presente em Freud desde meados da década de 1890, quando é sugerido, em suas correspondências com Fliess (Masson, 1986) que a perversão é a consequência da não ocorrência da defesa, pensada aqui como o recalque (sugestão feita de maneira subentendida na carta de 6 de dezembro de 1986). Na carta de 11 de janeiro de 1897, Freud fala das perversões como algo animalesco, ainda mais primitivo; na de 24 de janeiro desse mesmo ano, já de forma direta, o autor afirma que "é como se, nas perversões, das quais a histeria é o negativo, estivéssemos diante de um remanescente de um culto sexual primitivo" (p. 228).

Mais próximo ao texto dos Três ensaios sobre a teoria da sexualidade também encontramos afirmações semelhantes. A primeira em uma nota de rodapé, no capítulo XII do texto Psicopatologia da vida cotidiana (Freud, 1901/1996m), na qual o fundador da psicanálise assevera que as fantasias dos histéricos, sobretudo as de maus tratos, assemelham-se às queixas dos paranoicos perseguidos, mas que as encontramos com conteúdo idêntico na satisfação dos apetites sexuais dos perversos.

Para Freud (1901/1996g), portanto, a neurose seria o negativo da perversão no momento em que aquela se constitui de exacerbado recalcamento do conteúdo sexual, ao passo de que, na última, tal conteúdo aparece de forma clara, ausente do sentimento de nojo ou culpa. Isso pode ser confirmado no trecho em que o autor afirma que "todos os psiconeuróticos são pessoas de inclinações perversas fortemente acentuadas, mas recalcadas e tornadas inconscientes no curso de seu desenvolvimento" (p. 56). Continuando, temos a segunda aparição da afirmação freudiana, agora de forma direta. Vejamos:

As psiconeuroses são, por assim dizer, o negativo das perversões. Nos neuróticos, a constituição sexual, na qual está contida a expressão da hereditariedade, atua em combinação com as influências acidentais de sua vida que possam perturbar o desenvolvimento da sexualidade normal. O curso d'água que encontra um obstáculo em seu leito reflui para leitos antigos que antes pareciam destinados a permanecer secos. As forças impulsoras da formação dos sintomas histéricos não provêm apenas da sexualidade normal recalcada, mas também das moções perversas inconscientes (Freud, 1901/1996g, p. 56, grifo do autor).

\footnotetext{
${ }^{6} \mathrm{Na}$ Edição Standard Brasileira, a editora Imago optou por traduzir tal título para A Negativa. Tal escolha de tradução contribui para aumentar a confusão entre os termos.
} 
Entretanto, enquanto na neurose há o mecanismo de recalque - inclusive dos conteúdos perversos -, na perversão temos o desmentido tal como apresentado no texto sobre o Fetichismo (Freud, 1927/1996f). Nele, o autor discorre a respeito de um paciente que relatava sobre um certo vislumbre [Glance] no nariz - ou seja: o nariz como objeto de fetiche. Nesse momento, o fetichismo já se refere a algo da perversão como entidade nosológica, ao lado das demais, principalmente no que diz respeito às neuroses - seu negativo. Podemos, então, falar de traços perversos (ou perversões negativas) como elementos estruturais nas neuroses causadores de sintomas, visto que esses advêm de uma fase inicial do desenvolvimento: a infância.

Isso pode ser muito bem percebido quando Freud (1919/1996e) destaca, em Bate-se em uma criança, que, quando o processo de recalcamento não ocorre (assim como a sublimação ou uma formação reativa), "a perversão persiste até a maturidade; e sempre que encontramos uma aberração sexual em adultos perversão, fetichismo, inversão - temos motivos para esperar que a investigação anamnésica revele um evento como o que sugeri, que conduza a uma fixação na infância" (p. 196). Em outras palavras, uma perversão "que persista por toda a vida, uma perversão que consuma toda a vida sexual do sujeito" (p. 205).

Temos, portanto, de um lado, a perversão como uma entidade nosológica em contraste com as tendências perversas dos neuróticos de outro. Visto que as neuroses são o negativo da perversão, percebe-se a necessidade de se realizar uma breve distinção entre traços perversos comuns a todos os indivíduos a perversões propriamente ditas - o que será contemplado mais adiante. Antes, porém, vejamos a crítica lacaniana à frase de Freud.

\section{A crítica lacaniana - o inconsciente a céu aberto}

Para visualizarmos melhor a crítica lacaniana à expressão freudiana de que a neurose é o negativo da perversão, torna-se importante a discussão de uma outra expressão utilizada por Lacan: a expressão a céu aberto (à ciel ouvert, no original francês), que seria correspondente ao português ao ar livre. Tal expressão não é utilizada por Lacan no contexto que ficou conhecido entre os psicanalistas, que seria a maneira privilegiada de se apresentar do Inconsciente nos casos de pacientes psicóticos. Essa expressão pode ser encontrada apenas na primeira clínica lacaniana, entre os anos de 1955 e 1966, a partir do momento que surge - na classe de 14 de dezembro de 1955 do Seminário 3 (Lacan, 1955-56/2002) até a classe de 20 de abril de 1966 do Seminário $13^{7}$ (Lacan, 1965-66/2018), passando por outros seminários nesse intervalo e por dois textos dos Escritos (Lacan, 1998b). Com esse roteiro em mente, faremos um pequeno percurso com a intenção de compreender melhor o que essa expressão significa no contexto da teoria lacaniana.

O sentido dessa expressão, quando utilizado por Lacan, é sempre o mesmo. Ele utiliza tal locução para designar algo que pode ser observado às claras, abertamente, à descoberto. Essas são, inclusive, as opções de tradução escolhidas pela editora Zahar, que publica os textos estabelecidos por Jacques-Alain Miller - a versão oficial dos textos lacanianos no Brasil. Podemos dividir as aparições da expressão "a céu aberto", na obra lacaniana, em três grupos:

No primeiro deles, a expressão surge com o sentido de algo fácil de ser observado, às claras. É nesse contexto que a encontramos no Seminário 4 (Lacan, 1956-57/1995), das seguintes formas: "não somente esta sugestão existe no caso do pequeno Hans, mas vamos vê-la eclodir abertamente" ${ }^{\prime}$ (p. 262); e "se essa análise é privilegiada, é porque nela vemos produzir-se abertamente a transição que faz passar a criança da dialética imaginária do jogo intersubjetivo com a mãe em torno do falo para o jogo da castração na relação com o pai”9 (p. 279). No Seminário 5 (Lacan, 1957-58/1999), podemos encontrá-la da seguinte maneira: "na tirada espirituosa, é às claras que a bola

\footnotetext{
${ }^{7}$ Este texto encontra-se em nossas referências com o título O objeto da psicanálise.

${ }^{8}$ Em pontos como este, em que a tradução brasileira não traz a expressão a céu aberto, acrescentaremos o original francês, deixando a expressão grifada para conferência. Neste caso, "Non seulement cette suggestion existe dans le cas du petit Hans, mais nous la voyons s'étaler à ciel ouvert” (Lacan, 1956-57/1994, p. 256).

${ }^{9}$ No original: "Si cette analyse est privilégiée, c'est que nous y voyons se produire à ciel ouvert la transition qui fait passer l'enfant de la dialectique imaginaire du jeu intersubjectif avec la mère autour du phallus, au jeu de la castration dans la relation avec le père” (Lacan, 1956-57/1994, p. 274).
} 
é rebatida entre a mensagem e o Outro, e que produz o efeito original que é próprio dela"10 (p. 97).

Ainda com esse mesmo sentido, podemos encontrar a expressão no Seminário 6 (Lacan, 1958/2016, p. 116) de dois modos: "mas é precisamente no caso em que esse momento, essa etapa da experiência do sujeito está a céu aberto que podemos, como diria o sr. de La Palice, vê-la e tocá-la, além de avaliar seu alcance"; e "basta observar uma criança para ver essa função essencial operando a céu aberto sob todas as suas formas" (p. 121).

Mantendo-se ainda nesse primeiro grupo, temos no Seminário 11 (Lacan, 1964/1998e) o seguinte: "certamente que a condensação significante, com seu efeito de metáfora, podemos observá-la a céu aberto, na menor metáfora poética" ${ }^{11}$ (p. 234) e, no Seminário 13 (Lacan, 1965-66/2018, p. 340, grifo do autor), temos: "quando se trata de Sócrates, parece-me difícil não compreender a coerência do conjunto de seu aparelho, sobretudo dado que tal aparelho estava lá para funcionar o tempo todo a céu aberto".

Podemos encontrar outros dois exemplos ainda com o mesmo sentido - de observar algo às claras nos seguintes textos incluídos na coletânea Escritos: primeiro em Função e campo da fala e da linguagem em psicanálise (Lacan, 1956/1998c, p. 266), no qual lemos que "a onipresença do discurso humano talvez possa, um dia, ser abarcada sob o céu aberto de uma onicomunicação de seu texto"; e também no texto Subversão do sujeito e dialética do desejo no inconsciente freudiano (Lacan, 1960/1998f), no qual se lê sobre os últimos desenvolvimentos da topologia lacaniana até aquela data. Nesse texto, o autor intenta "introduzir um certo grafo que prevenimos garantir apenas, entre outros, o emprego que faremos dele, tendo sido construído e ajustado a céu aberto para situar, em sua disposição em patamares, a estrutura mais amplamente prática dos dados de nossa experiência" (p. 819).

Esses exemplos se apresentam com um sentido que parece ser corriqueiro na língua francesa, ou que
Lacan utilizava com certa frequência. Pudemos ver diversos temas nos quais a expressão a céu aberto surgiu sem nenhuma ligação com o que buscamos em nosso trabalho, que é a crítica lacaniana da frase freudiana de que a neurose é o negativo da perversão. Cabe também notar que, justamente quando focamos esse sentido da expressão (às claras), não há uma escolha por parte dos tradutores para qual termo utilizar em português - daí encontramos abertamente, às claras e até mesmo a céu aberto, mas todas essas traduções mantêm a coerência com o que Lacan parecia querer dizer naquele momento.

Podemos agora ressaltar um segundo grupo, com apenas um exemplo, da expressão a céu abertoalgo que pode ser observado às claras no discurso de um paciente, sem que, aparentemente, passe pelo recalque. No Seminário 3 (Lacan, 1955-56/2002) encontramos, em apenas uma lição (do dia 14 de dezembro de 1955), um breve comentário do autor sobre uma de suas apresentações de pacientes, e é a primeira vez que ele utilizaria a expressão que está em nosso foco no momento. É interessante notar que, apesar de estarmos em um seminário dedicado às psicoses, Lacan utiliza-se de um caso de neurose para introduzir o tema. Nas palavras dele,

era um caso clínico que eu certamente não tinha escolhido, mas que de algum modo fazia inconsciente funcionar a descoberto, em sua dificuldade de entrar no discurso analítico. Ele o fazia funcionar a descoberto, porque, em virtude de circunstâncias excepcionais, tudo o que em outro sujeito haveria entrado no recalque, encontrava-se nele suportado por uma outra linguagem (Lacan, 1955-56/2002, p. 73) ${ }^{12}$.

O motivo desse funcionamento diferenciado está na história pregressa do paciente. Ele fora criado em Paris, filho único de pais muito fechados em suas próprias leis e que apenas falavam entre si em um dialeto

\footnotetext{
${ }^{10}$ No original: “Dans le trait d'esprit, c'est à ciel ouvert que la balle est renvoyée entre message et Autre, et qu'elle produit l'effet original qui est le propre de celui-ci" (Lacan, 1957-58/1998d, p. 93).

${ }^{11}$ Parece ter ocorrido aqui um erro de grafia na tradução brasileira, em que lemos "certamente que a condenação significante" no texto brasileiro, lemos "bien sûr, la condensation signifiant” no texto em francês (Lacan, 1964/1973, p. 275). Assim sendo, tomamos a liberdade de corrigir a edição brasileira em nossa citação, trocando condenação por condensação.

${ }^{12}$ No original: “cas clinique que je n'ai certainement pas choisi, mais qui était extrêmement intéressant parce qu'il faisait en quelque sorte jouer à ciel ouvert la relation d'inconscient dans sa difficulté d'arriver à passer dans le discours analytique: il le faisait jouer à ciel ouvert parce qu'en raison de circonstances exceptionnelles, tout ce qui chez un autre sujet comparable eut pu passer dans le mécanisme du refoulement, se trouvait chez lui supporté par un autre langage" (Lacan, 1955-56/1981, p. 71)
} 
corso. Esse paciente acabou aprendendo duas línguas o francês e o dialeto corso - e isso acabou criando para ele dois mundos: um familiar e outro compartilhado com o mundo externo a seus laços familiares. Tal dialeto acabou se tornando seu mundo familiar, um dialeto no qual depositava todas as queixas e questões relacionadas à família. Para o mundo externo, havia o francês.

Tudo isso deixaria algo bem visível na clínica, o que Lacan tomou como o mais demonstrativo em relação ao caso. Primeiramente, uma dificuldade de retomar qualquer assunto no dialeto utilizado em sua infância, por mais que o analista insistisse. $\mathrm{O}$ outro aspecto visível clinicamente era uma neurose com um caráter regressivo, como diz Lacan com reservas, em especial no que se refere à sua maneira de praticar sua sexualidade, confundida no plano imaginativo com a atividade regressiva das funções excrementícias. Aqui surge o ápice da exposição lacaniana desse caso. Vejamos:

mas tudo o que era da ordem do que é habitualmente recalcado, todo o conteúdo expresso comumente por intermédio dos sintomas neuróticos, estava ali perfeitamente límpido, e eu não tinha nenhuma dificuldade em fazer com que ele o exprimisse. Ele o exprimia tanto mais facilmente pois que isso era suportado pela linguagem dos outros (Lacan, 1955-56/2002, p. 74).

Passemos ao terceiro grupo, o que mais nos interessa: as críticas lacanianas da frase freudiana sobre a relação entre a perversão e a neurose. É interessante notar que, nesse sentido, a edição brasileira sempre traz a tradução literal por céu aberto. Vejamos nas palavras de Lacan (1956-57/1995, p. 115), em seu Seminário 4:

diria, mesmo, mais: temos no próprio Freud um exemplo que prova que sua fórmula, segundo a qual a perversão é o negativo da neurose, não deve ser tomada como o foi durante muito tempo, como se devêssemos simplesmente entender que o que está oculto no inconsciente, quando estamos em presença de um caso neurótico, esteja a céu aberto na perversão, e de certa maneira em estado livre.

No Seminário 5 (Lacan, 1957-58/1999, p. 168) encontramos, também nesse terceiro grupo, a seguinte fala: "o que se invertera na neurose era visto às claras na perversão. Posto que a perversão não teria sido recalcada nem passado pelo Édipo, o inconsciente ficava exposto a céu aberto". Já no texto Subversão do sujeito e dialética do desejo no inconsciente freudiano (Lacan, 1960/1998f, p. 839), deparamo-nos com outra pontuação lacaniana em relação à perversão como negativo da neurose: "eis o que fornece o sentido da pretensa perversão situada no princípio da neurose. Ela existe no inconsciente do neurótico como fantasia do Outro. Mas isso não quer dizer que, no perverso o inconsciente esteja plenamente a céu aberto". Esses últimos exemplos trazem uma significação muito mais próxima da que estamos acostumados a ouvir no jargão psicanalítico, de um funcionamento do inconsciente a céu aberto.

Temos, então, algo interessante: nos momentos em que Lacan trabalha com a ideia de um funcionamento a céu aberto do Inconsciente, ele se reporta ou à neurose (como no segundo grupo) ou às perversões (em suas críticas à frase freudiana). Em nenhum de seus textos encontramos Lacan dizendo a frase que se tornou jargão no meio psicanalítico de que, na psicose, o Inconsciente está a céu aberto. Para Lacan (1960/ 1998f), na perversão, o Inconsciente não está totalmente a céu aberto, visto que ela (a perversão) existiria no Inconsciente do neurótico como uma fantasia do Outro. E, ainda mais, ressalta que também o perverso se defende à sua maneira em seu desejo, já que o desejo é uma defesa, uma proibição em se ultrapassar um limite no gozo.

Para um melhor entendimento de como essa crítica lacaniana se dá, precisamos apresentar uma breve descrição, ainda que bastante rudimentar, de como se organizam as construções nosológicas de Freud e Lacan - uma vez que isso nos dará uma visão mais clara de sua crítica, assim como da posição freudiana. Passemos a esse ponto.

\section{Discussão}

\section{As perversões propriamente ditas ou perversões positivas}

No texto sobre o Fetichismo, Freud (1927/1996f) discorre sobre a ausência de uma definição de fatores que levam, de fato, à perversão. Ou seja, os fatores que levam o sujeito a optar pelo mecanismo do desmentido ao invés do recalque. Entretanto, sabemos que, na perversão propriamente dita, tal mecanismo tem por finalidade desmentir a castração de forma que a mãe continua a possuir o falo - algo que pode se 
aproximar da psicose no momento em que o Eu repudia certa parcela da realidade (no caso da perversão, a castração da mãe), mesmo que isso se dê de formas diferentes nas duas entidades nosológicas. Nesse sentido, cabe-nos uma distinção entre ambas, pois, enquanto na psicose há uma reconstrução da realidadealucinação-, na perversão temos a recusa, ou o desmentido da mesma - fetichismo (Valas, 1990; Mendonça, 2012). Roudinesco e Plon (1998, p. 585) afirmam que há

uma clivagem do eu que caracteriza não somente a psicose, mas igualmente a perversão. A partir desse ponto, a perversão se inscreveu numa estrutura tripartite. Ao lado da psicose, definida como a reconstrução de uma realidade alucinatória, e da neurose, resultante de um conflito interno seguido de recalque, a perversão aparece como uma renegação ou um desmentido da castração, com uma fixação na sexualidade infantil.

De forma geral, em Freud, o recalque original [Urverdrängung] aconteceria inicialmente para todos os indivíduos. Entretanto, o recalque propriamente dito [Verdrängung] perdura apenas na neurose, ao passo de que o desmentido [Verleugnung] prevalece nas demais entidades. Temos, assim, a neurose de um lado e as psicoses e perversões do outro, sendo que nas últimas "teríamos uma contestação desta realidade, mais especificamente, da realidade da castração" (Mendonça, 2018, p. 43). Na psicose ainda haveria um tipo de recalque mais severo, no qual o sujeito rejeita a realidade como um todo, denominado Verwerfung. As alucinações seriam justamente o retorno desse conteúdo rejeitado (Mendonça, 2018). A nosologia freudiana pode ser resumida por meio do esquema abaixo:

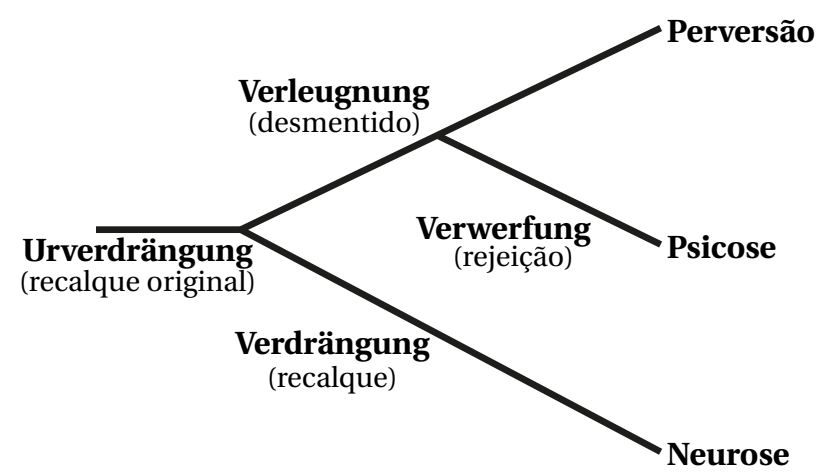

Figura 1

Esquema simplificado da nosologia freudiana.

Fonte: Mendonça, 2018, p. 43.
Consideramos necessária a realização de um pequeno parênteses para que a crítica de Lacan à nosologia freudiana pudesse ser resumidamente apontada. Como visto anteriormente, para o analista francês, a neurose não seria o negativo da perversão; estas estariam juntas em contraponto à psicose - estrutura de maior destaque na obra lacaniana. Em Lacan, não está bem definido a presença de um recalque originário, ficando o recalque como mecanismo apenas para as neuroses, enquanto nas psicoses temos a foraclusãotradução escolhida pelo autor para Verwerfung e, por fim, o desmentido nas perversões (Mendonça, 2018). Assim, neurose e perversão encontram-se do mesmo lado, tal como demonstrado no esquema abaixo:

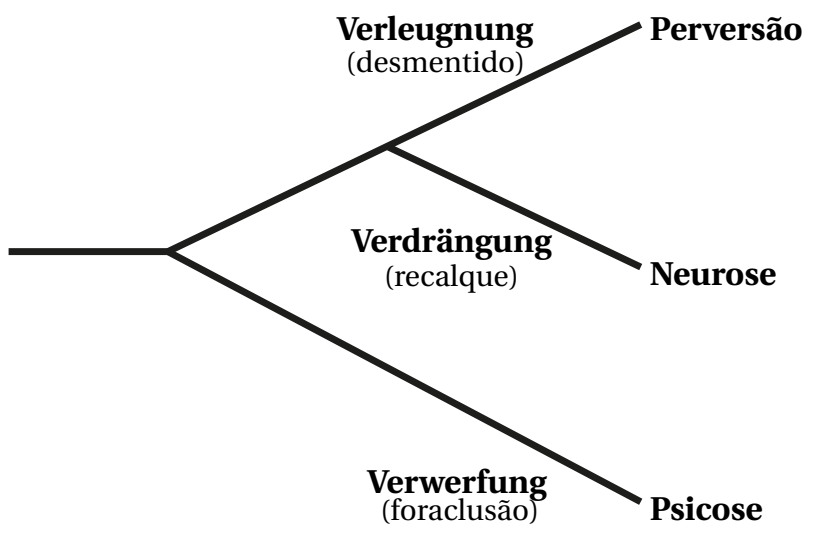

Figura 2

Esquema simplificado da nosologia lacaniana.

Fonte: Mendonça, 2018, p. 47.

Vemos nesses dois esquemas que, para Freud, a neurose é o negativo da perversão, pois elas seguem caminhos diversos. Para Lacan, o mesmo não se dá, e podemos entender melhor sua crítica à proposta freudiana.

Nesse sentido, uma distinção entre psicose e perversão nos leva novamente a perceber o atributo estrutural dessa segunda, podendo ser classificada de maneira nosológica, paralelamente às demais. Visto isso, cabe-nos também tentar, mesmo que de maneira breve, discernir a perversão como entidade nosológica daqueles traços perversos presentes nas neuroses. "Justamente no campo da vida sexual é que se tropeça com dificuldades peculiares e realmente insolúveis, no momento, quando se quer traçar uma fronteira nítida entre o que é mera variação dentro da amplitude do fisiológico e o que constitui sintomas patológicos" (Freud, 1905/1996n, p. 152). 
Ao retornarmos aos Três ensaios sobre a teoria da sexualidade (Freud, 1905/1996n) - principalmente quando o mestre de Viena discorre a respeito das aberrações sexuais -, podemos encontrar afirmações que nos levam a crer que os critérios para realizar tal diferenciação estão relacionados a aspectos como fixação, especificidade, intensidade e exclusividade direcionados aos alvos sexuais, além da ausência de qualquer pudor ou asco na realização de tais atos.

As ditas transgressões anatômicas e os desvios quanto ao objeto sexual, assim como discutido anteriormente, são tidos como atos perversos pois fogem daquilo que objetiva única e exclusivamente à reprodução. Isso, porém, não diz de uma perversão propriamente dita, mas sim de traços perversos, com exceção daqueles que

afastam-se tanto do normal em seu conteúdo que não podemos deixar de declará-las 'patológicas', sobretudo nos casos em que a pulsão sexual realiza obras assombrosas (lamber excrementos, abusar de cadáveres) na superação das resistências (vergonha, asco, horror ou dor) (Freud, 1905/1996n, p. 152).

Ou ainda, complementa Freud (1905/1996n, p. 140) "em casos em que se escolhem pessoas sexualmente imaturas (crianças) como objetos sexuais são desde logo encarados como aberrações esporádicas". De acordo com Valas (1990, p. 28),

o extraordinário polimorfismo das manifestações da sexualidade no homem, o fato de que seus desvios intrínsecos se encontram em todos os seres humanos, tudo isso cria dificuldades para Freud, ao definir a perversão. Ele formula, então, que para além de certas manifestações incontestavelmente patológicas (coprofagia, necrofilia), só se pode distinguir a perversão da normalidade porque a perversão se caracteriza por uma fixação prevalente, até mesmo total, do desvio quanto ao objeto, e pela exclusividade da prática quanto ao desvio com relação ao objeto.

Quanto a isso, Freud (1905/1996n) menciona a fixação por atos sexuais preliminares que chegam a substituir o fim sexual. O simples tocar, olhar e exibir não são suficientes para constituir uma perversão positiva, mas o torna a partir do momento em que esses atos substituem o objetivo sexual final; ou mesmo se o prazer em ver é restrito aos genitais ou estiver relacionado à supressão da vergonha. Tais práticas voyeuristas e/ou exibicionistas são, de acordo com Freud, barradas pelo pudor em indivíduos ditos normais.

O sadismo e o masoquismo também se tornam patológicos quando a tendência agressiva/destrutiva presente em todo ser humano se torna erotizada, ou seja: uma extrema agressão relacionada à sexualidade. Entretanto, assim como nos indica Valas (1990), o sadismo e o masoquismo não devem ser confundidos com as pulsões sadomasoquistas, que estão relacionadas à pulsão de morte. Entretanto, tais componentes podem se desprender de seu desenvolvimento normal e tornar-se independentes, tomando conta de toda a vida sexual do indivíduo (Freud, 1919/1996e). O masoquismo feminino (no sentido de ser castrado, copulado ou dar à luz) está relacionado ao ato sexual, mas não necessariamente configura-se uma perversão a menos que haja uma erotização da dor, pois, como bem salienta Valas (1990, p. 106), o objetivo pulsional não é o de "infligir a dor, mas dominar o objeto". A erotização da dor, seja no lugar do sádico ou do masoquista, é o que configura a posição perversa nesse sentido.

O fetichismo, por via de regra, torna-se perverso no momento em que há uma intensa fixação por objetos externos ao corpo, tal como sapatos, roupasíntimas etc., ou por partes anatômicas que não estão relacionadas ao ato sexual, como pés, cabelos, dentre outros. "O caso só se torna patológico quando o anseio pelo fetiche se fixa, indo além da condição mencionada, colocando-se no lugar do alvo sexual normal, e ainda, quando o fetiche se desprende de determinada pessoa e se torna o único objeto sexual" (Freud, 1905/1996n, p. 146). De acordo com o fundador da Psicanálise, o fetiche se define a partir da última impressão que o sujeito possui antes do trauma ao descobrir que sua mãe não possui um pênis. Um exemplo disso ocorre com roupas íntimas "que tão frequentemente são escolhidas como fetiche, cristalizam o momento de se despir, o último momento em que a mulher ainda podia ser encarada como fálica" (Freud, 1927/1996f, p. 162). O fetiche, portanto, está quase que invariavelmente ligado a especificidades de características, mas é fato que este sempre procura encobrir a castração da mulher; logo, a própria castração fetichista.

Se levarmos em conta esses aspectos, tão presentes nos Três ensaios sobre a teoria da sexualidade 
(Freud, 1905/1996n), a perversão decorre da “impossibilidade de a corrente genital da sexualidade impor-se perante às demais, em função de uma fixação, ocorrida na infância, que elevaria uma corrente pré-genital à condição de eixo organizador da vida sexual" (Ferraz, 2010, p. 33). Ou seja: o perverso ainda possui vínculos muito fortes com aquela sexualidade perverso-polimorfa infantil, ainda que em uma dinâmica um tanto quanto diferente dessa mesma.

O conceito de perversão foi, entretanto, desenvolvido ao longo de toda a obra freudiana sem que houvesse desconsideração de suas formulações anteriores a respeito do tema. Desse modo, a concepção do mecanismo do desmentido consolidou-se como um elemento de grande relevância para o estudo das perversões - inclusive por Lacan e demais teóricos da psicanálise, dentro desse modo de subjetivação em que há a contestação da castração. No desmentido, portanto, "desaparecem as diferenças, limites e normas, visto que a função paterna fica enfraquecida e os impulsos incestuosos não encontram delimitação clara" (Ferraz, 2010, p. 44), assim como os demais impulsos relacionados às demais práticas sexuais, ausentes de qualquer repressão. De maneira geral, ao acreditar que sua mãe ainda possui um falo, o falo do perverso não corre o risco de ser castrado, fazendo com que o mesmo possa subverter a lei simbólica (Valas, 1990).

A perversão propriamente dita é tida como entidade nosológica a partir de certo momento na obra freudiana, marcada pela forma que o indivíduo lida com a castração e, subsequentemente, com as relações dele com seus objetos de investimento. A afirmação freudiana de que a neurose é o negativo da perversão aponta para essas diferenças subjetivas entre perversões positivas e negativas, sendo que, de acordo com Valas (1990, p. 105), "nos neuróticos, a atuação dos fantasmas perversos permanece isolada, ocasional, enquanto nos perversos a conduta sexual estereotipada, fixada em modos particulares e repetitivos, evoca uma noção de uma estrutura subjacente que a determina". Nesse sentido, a perversão em si está relacionada com a forma pela qual o sujeito lida com o objeto, e não o objeto em si, ao passo de que nem mesmo a fantasia perversa pode dizer de uma perversão propriamente dita visto que as mesmas estão igualmente presentes nos neuróticos, que, ao contrário dos primeiros, raramente as colocam inteira e definitivamente em cena.

\section{Considerações finais}

Freud (1905/1996n), em seus Três ensaios sobre a teoria da sexualidade, realizou grandes marcos teóricos ao afirmar a presença de uma sexualidade infantil, além de constatar que a perversão está presente nas fantasias de todos os seres humanos em algum nível. É nesse sentido, inclusive, que o autor realiza a afirmativa de que a neurose é o negativo da perversão - tal como uma fotografia antiga, na qual temos a inversão das cores, transformando a imagem em seu avesso. Temos, assim, as perversões negativas, que se constituem de fantasias perversas, por vezes causadoras de sintomas neuróticos, em oposição às perversões positivas, ou seja: quando essas fantasias são colocadas em prática sem a presença de sentimentos de asco, vergonha ou pudor.

As perversões propriamente ditas são consideradas por Freud (1905/1996n), no início de seus estudos sobre a temática, uma fixação nas fases pré-genitais do desenvolvimento - fixação essa que abrange toda a vida sexual do indivíduo. Apesar das dificuldades para delimitar uma fronteira entre o normal e o patológico, há critérios que podem diferenciar as perversões propriamente ditas daquelas fantasias neuróticas, que estariam relacionadas à maneira com a qual o perverso coloca em prática tais fantasias intimamente associadas a aspectos como fixação, especificidade, intensidade e exclusividade direcionados aos alvos sexuais, além da ausência de qualquer pudor ou asco na realização de tais atos. As relações sadomasoquistas, o voyeurismo/exibicionismo, o tocar, a demora nos atos preliminares, dentre outras, depende da forma com que o sujeito as enxerga e as exerce, sendo a simples presença dessas fantasias insuficiente para delimitar uma perversão positiva.

Em um outro momento da obra freudiana (Freud, 1919/1996e), o complexo de Édipo entra em cena como principal gênese das perversões, marcado por fantasias sadomasoquistas de surra comuns a todos os indivíduos. As mesmas, porém, ganham um status diferenciado em 1927 com o artigo sobre o fetichismo em que a perversão passa a ser considerada uma entidade nosológica, ao lado da neurose e da psicose, por meio do conceito de desmentido como seu principal mecanismo. Ao deparar-se com a castração, o sujeito perverso, ao contrário do neurótico que opta pelo recalque, a contesta, carregando a crença de que a mulher nunca foi castrada. Assim, contestando a castração, não há mais temor quanto 
à perda do falo, levando o perverso a executar ações isento de interdições simbólicas.

Esse percurso teórico não só modificou o conceito de perversão vigente na época de Freud como também serviu de base para o desenvolvimento de teorias posteriores a respeito do tema, como realizado por Lacan. O termo perversão, ainda hoje, remete à ideia de imoralidade, promiscuidade e maldade. Entretanto, o próprio Freud (1905/1996n) diz da necessidade de uma contextualização histórica, social e cultural no que tange à delimitação entre o normal e o patológico - seja no tocante ao campo das perversões ou na psicopatologia em geral. Portanto, por tratar-se de questões que envolvem a subjetividade, não podemos deixar de atentar para o fato de que as perversões, assim como qualquer outra entidade nosológica, estabelecem-se a partir do posicionamento do sujeito frente ao fenômeno da castração e, para além disso, da forma que este estabelece relações com seus objetos de satisfação.

\section{Referências}

Ferraz, F. C. (2010). Perversão (5a ed.). Casa do Psicólogo.

Freud, S. (1996a). Além do princípio do prazer. In S. Freud. Edição standard brasileira das obras psicológicas completas de Sigmund Freud (J. Strachey, Trad., Vol. 18, pp. 11-72). Imago. (Trabalho original publicado em 1920)

Freud, S. (1996b). Análise de uma fobia em um menino de cinco anos. In S. Freud. Edição standard brasileira das obras psicológicas completas de Sigmund Freud (J. Strachey, Trad., Vol. 10, pp. 11-133). Imago. (Trabalho original publicado em 1909)

Freud, S. (1996c). Uma breve descrição da psicanálise. In S. Freud. Edição Standard Brasileira das Obras Psicológicas Completas de Sigmund Freud (J. Strachey, Trad., Vol. 19, pp. 213-236). Imago. (Trabalho original publicado em 1923)

Freud, S. (1996d). Cinco lições de psicanálise. In S. Freud. Edição standard brasileira das obras psicológicas completas de Sigmund Freud (J. Strachey, Trad., Vol. 11, pp. 15-66). Imago. (Trabalho original publicado em 1909)

Freud, S. (1996e). Uma criança é espancada: uma contribuição ao estudo da origem das perversões sexuais. In S. Freud. Edição standard brasileira das obras psicológicas completas de Sigmund Freud (J. Strachey, Trad., Vol. 17, pp. 189-216). Imago. (Trabalho original publicado em 1919)

Freud, S. (1996f). Fetichismo. In S. Freud. Edição standard brasileira das obras psicológicas completas de Sigmund Freud (J. Strachey, Trad., Vol. 21, pp. 153-164). Imago. (Trabalho original publicado em 1927)

Freud, S. (1996g). Fragmento da análise de um caso de histeria. In S. Freud. Edição standard brasileira das obras psicológicas completas de Sigmund Freud (J. Strachey, Trad., Vol. 7, pp. 13-116). Imago. (Trabalho original publicado em 1901)

Freud, S. (1996h). Os instintos e suas vicissitudes. In S. Freud. Edição standard brasileira das obras psicológicas completas de Sigmund Freud (J. Strachey, Trad., Vol. 14, pp. 115-144). Imago. (Trabalho original publicado em 1915)

Freud, S. (1996i). Moral sexual "civilizada" e doença nervosa moderna. In S. Freud. Edição standard brasileira das obras psicológicas completas de Sigmund Freud (J. Strachey, Trad., Vol. 9, pp. 165-186). Imago. (Trabalho original publicado em 1908)

Freud, S. (1996j). A negativa. In S. Freud. Edição standard brasileira das obras psicológicas completas de Sigmund Freud (J. Strachey, Trad., Vol. 19, pp. 263-271). Imago. (Trabalho original publicado em 1925)

Freud, S. (1996k). O problema econômico do masoquismo. In S. Freud. Edição standard brasileira das obras psicológicas completas de Sigmund Freud (J. Strachey, Trad., Vol. 19, pp. 175-190). Imago. (Trabalho original publicado em 1924)

Freud, S. (1996l). Sobre a psicanálise. In S. Freud. Edição standard brasileira das obras psicológicas completas de Sigmund Freud (J. Strachey, Trad., Vol. 12, pp. 223-231). Imago. (Trabalho original publicado em 1911)

Freud, S. (1996m). Sobre a psicopatologia da vida cotidiana. In S. Freud. Edição standard brasileira das obras psicológicas completas de Sigmund Freud (J. Strachey, Trad., Vol. 6). Imago. (Trabalho original publicado em 1901)

Freud, S. (1996n). Três ensaios sobre a teoria da sexualidade. In S. Freud. Edição standard brasileira das obras psicológicas completas de Sigmund Freud (J. Strachey, Trad., Vol. 7, pp. 117-231). Imago. (Trabalho original publicado em 1905)

Freud, S. (1999). Drei Abhandlungen zur Sexualtheorie. In S. Freud. Gesammelte Werke (Vol. 5, pp. 27-145). Fischer Taschenbuch Verlag. (Trabalho original publicado em 1905) 
Freud, S. (2016). "Bate-se numa criança”: Contribuição para o estudo das perversões sexuais. In S. Freud. Obras incompletas de Sigmund Freud (M. R. S. Moraes, Trad., Vol. 5, pp. 285-311). Autêntica. (Trabalho original publicado em 1919)

Lacan, J. (1973). Le seminaire, livre XI : Les quatre concepts fondamentaux de la psychanalyse. Éditions du Seuil. (Trabalho original publicado em 1964)

Lacan, J. (1981). Le seminaire, livre III : Les psychoses. Éditions du Seuil. (Trabalho original publicado em 1955-56)

Lacan, J. (1994). Le seminaire, livre IV : La relation d'objet. Éditions du Seuil. (Trabalho original publicado em 1956-57)

Lacan, J. (1995). O seminário, livro 4: A relação de objeto (D. D. Estrada, Trad.). Zahar. (Trabalho original publicado em 1956-57)

Lacan, J. (1998a). A coisa freudiana ou o sentido do retorno a Freud em psicanálise. In J. Lacan. Escritos (V. Ribeiro, Trad., pp. 402-437). Zahar. (Trabalho original publicado em 1955)

Lacan, J. (1998b). Escritos (V. Ribeiro, Trad.). Zahar.

Lacan, J. (1998c). Função e campo da fala e da linguagem em psicanálise. In J. Lacan. Escritos (V. Ribeiro, Trad., pp. 238-324). Zahar. (Trabalho original publicado em 1956)

Lacan, J. (1998d). Le seminaire, livre V : Les formations de l'inconscient. Éditions du Seuil. (Trabalho original publicado em 1957-58)

Lacan, J. (1998e). O seminário, livro 11: Os quatro conceitos fundamentais da psicanálise (M. D. Magno, Trad., 2a ed.). Zahar. (Trabalho original publicado em 1964)

Lacan, J. (1998f). Subversão do sujeito e dialética do desejo no inconsciente freudiano. In J. Lacan. Escritos (V. Ribeiro, Trad., pp. 807-842). Zahar. (Trabalho original publicado em 1960)

Lacan, J. (1999). O seminário, livro 5: As formações do inconsciente (V. Ribeiro, Trad.). Zahar. (Trabalho original publicado em 1957-58)

Lacan, J. (2002). O seminário, livro 3: As psicoses (A. Menezes, Trad., 2a ed. rev.). Zahar. (Trabalho original publicado em 1955-56)

Lacan, J. (2016). O seminário, livro 6: O desejo e sua interpretação. Zahar. (Trabalho original publicado em 1958-59)

Lacan, J. (2018). O objeto da psicanálise. Fórum do Campo Lacaniano de São Paulo. (Trabalho original publicado em 1965-66)

Masson, J. M. (1986). A correspondência completa de Sigmund Freud para Wilhelm Fliess - 1887-1904 (V. Ribeiro, Trad.). Imago.

Mendonça, R. L. (2012). O inconsciente a céu aberto e a transferência: O secretário do alienado como manejo clínico na psicose [Dissertação de mestrado]. Universidade Federal de São João del-Rei.

Mendonça, R. L. (2018). A realidade mostrada à maneira dos geômetras: Um estudo topológico sobre o conceito de realidade em Psicanálise [Tese de doutorado]. Universidade do Estado de Minas Gerais.

Roudinesco, E. (2016). Sigmund Freud na sua época e em nosso tempo. Zahar.

Roudinesco, E., \& Plon, M. (1998). Perversão. In E. Roudinesco, \& M. Plon. Dicionário de psicanálise (pp. 583-587).Zahar.

Valas, P. (1990). Freud e a perversão. Zahar.

\section{Roberto Lopes Mendonça}

Professor dos cursos de pós-graduação da Faculdade Pitágoras e do Grupo Unis.

E-mail: robertomendoncapsi@gmail.com

(1) https://orcid.org/0000-0002-6042-7546

\section{Mardem Leandro Silva}

Professor de Psicologia na Universidade do Estado de Minas Gerais (UEMG) e no Instituto Federal de Minas Gerais (IFMG), Bambuí - MG. Brasil.

E-mail: mardemls@yahoo.com.br

(1) https://orcid.org/0000-0001-7069-4608 


\section{Daniela Paula do Couto}

Doutoranda em Psicologia pela Universidade Federal de Minas Gerais (UFMG), Belo Horizonte - MG. Brasil.

E-mail:dp.couto@yahoo.com.br

(1) https://orcid.org/0000-0001-5315-4087

\section{Carlos Eduardo Rodrigues}

Professor da graduação e do programa de Pós-Graduação em Psicologia da Faculdade Pitágoras, Divinópolis MG. Brasil.

E-mail: kadurz@yahoo.com.br

(1) https://orcid.org/0000-0002-4468-7444

\section{Aline Aparecida Rocha Caetano}

Bacharel em Psicologia pela Universidade do Estado de Minas Gerais (UEMG), Divinópolis - MG. Brasil.

E-mail: alinerocha-c@hotmail.com

(1) https://orcid.org/0000-0002-0242-0813

\section{Elizabeth Fátima Teodoro}

Doutoranda em Psicologia pela Universidade Federal de São João del-Rei (UFSJ), São João del-Rei - MG. Brasil.

E-mail: elektraliz@yahoo.com.br

(1) https://orcid.org/0000-0003-0977-7265

Endereço para envio de correspondência:

Universidade do Estado de Minas Gerais. Av. Paraná, 3001, Jardim Belvedere. CEP 35501-170. Divinópolis - MG. Brasil.

Recebido 05/01/2019

Aceito 05/10/2020

Received 01/05/2019

Approved 10/05/2020

Recibido 05/01/2019

Aceptado 05/10/2020

Como citar: Mendonça, R. L., Silva, M. L., Couto, D. P., Rodrigues, C. E., Caetano, A. A. R., \& Teodoro, E. F. (2021). A neurose como negativo da perversão: Um estudo das perversões em Freud. Psicologia: Ciência e Profissão, 41, 1-16. https://doi.org/10.1590/1982-3703003218321

How to cite: Mendonça, R. L., Silva, M. L., Couto, D. P., Rodrigues, C. E., Caetano, A. A. R., \& Teodoro, E. F. (2021). Neurosis as negative of perversion: A study of perversions in Freud. Psicologia: Ciência e Profissão, 41, 1-16. https://doi.org/10.1590/1982-3703003218321

Cómo citar: Mendonça, R. L., Silva, M. L., Couto, D. P., Rodrigues, C. E., Caetano, A. A. R., \& Teodoro, E. F. (2021). La neurosis como negativa de la perversión: Un estudio de las perversiones en Freud. Psicologia: Ciência e Profissão, 41, 1-16. https://doi.org/10.1590/1982-3703003218321 